\title{
Commentary \\ Expanding the therapeutic repertoire of epidermal growth factor receptor blockade: radiosensitization
}

\author{
Julia MW Gee and Robert I Nicholson \\ Tenovus Centre for Cancer Research, Welsh School of Pharmacy, Cardiff University, Cardiff, UK \\ Corresponding author: JMW Gee (e-mail: gee@cardiff.ac.uk) \\ Published: 20 February 2003
}

Breast Cancer Res 2003, 5:126-129 (DOI 10.1186/bcr584)

(C) 2003 BioMed Central Ltd (Print ISSN 1465-5411; Online ISSN 1465-542X)

\begin{abstract}
Expression of epidermal growth factor receptor (EGFR) has been associated with radioresistance in cancer. Moreover, tumour cell recovery after irradiation paradoxically occurs, in part, as a result of activation of EGFR signalling by such treatment. A recent article by Huang, Li, Armstrong and Harari provides strong rationale for considering the anti-EGFR agent ZD1839 ('Iressa') as a radiosensitizing strategy. With the use of several in vitro and xenograft models of human squamous cell head and neck carcinoma, ZD1939 was shown to markedly improve radiotherapeutic response, with superior tumour inhibition and delayed tumour regrowth. Mechanisms underlying this effect included anti-proliferative and pro-apoptotic activity, with significant perturbation of tumour angiogenesis.
\end{abstract}

Keywords: angiogenesis, EGFR, radiotherapy, resistance, ZD1839

\section{Introduction}

Therapy with ionizing radiation provides a key management strategy for many epithelial tumour types. Radiotherapy forms part of the multidisciplinary approach to the treatment of breast cancer, and is now of routine value after conservative surgery to reduce locoregional recurrence. However, there are significant limitations of radiotherapy in many cancers. Some are intrinsically resistant to damage by ionizing radiation. Moreover, a proportion of cells can survive irradiation, with treatment inducing their proliferation to accelerate tumour cell repopulation during radiation challenge [1]. In total, such events result in a diminished response to radiation, resistant growth and poor local control. Knowledge of the molecular mechanisms employed by tumour cells to evade the inhibitory activity of radiotherapy is essential if we are to design novel treatment strategies rationally to improve its effectiveness.

Although various intrinsic and extrinsic factors have been implicated, the role played by growth factor signal transduction in radiation resistance is particularly fascinating. Of these, perhaps the most compelling data exist for the involvement of the epidermal growth factor receptor (EGFR/c-erbB1/HER1) pathway in determining radiosensitivity. Indeed, there has been a recent flourish of literature in this area, in part triggered by the availability of monoclonal antibodies and pharmacological inhibitors that can block EGFR. In this light, the recent article by Huang et al. [2] examines the anti-tumour activity of the EGFRselective tyrosine kinase inhibitor ZD1839 ('Iressa') in combination with radiotherapy, using several experimental models of human squamous cell head and neck carcinoma. Importantly, the study demonstrates superior antitumour potency with ZD1839 plus radiotherapy. It sheds light on the multiple mechanisms underlying this effect, notably improved anti-proliferative and pro-apopotic activity, as well as significant perturbation of angiogenesis, events that act cumulatively to limit cell recovery after irradiation and significantly delay tumour regrowth. Not only are such data highly supportive of a key role for EGFR in determining fundamental cancer cell biology and radioresponse, but, importantly, they confirm that anti-EGFR agents might provide considerable advantage as a radiosensitizing strategy in cancer management. 


\section{EGFR occupies a pivotal position in cancer cell biology}

EGFR is established as an important regulator of proliferation, cell survival, DNA damage repair, cell motility and invasive capacity. Furthermore, EGFR signalling promotes angiogenesis, an event essential for cancer cell viability, tumour growth and metastasis [3]. Not surprisingly, therefore, dysregulation of EGFR signalling has been closely associated with the initiation, growth and progression of the majority of human epithelial tumour types, including breast, non-small cell lung, colorectal, head and neck, ovarian, gastric and pancreatic cancer. EGFR dysregulation, commonly a consequence of receptor or ligand overexpression and hence enhanced autocrine signalling, invariably confers aggressive tumour biology in the clinic, and in some tumour types a poor prognosis [4]. In breast cancer, EGFR overexpression has been associated with reduced oestrogen receptor content, advanced clinical stage and shortened relapse-free survival [5].

\section{EGFR is associated with tumour cell escape from inhibition by radiotherapy}

EGFR dysregulation has been implicated in therapeutic resistance to diverse agents across many cancer types. Associations have been noted between EGFR overexpression and resistance to cytotoxic agents [6] and to anti-hormonal agents in breast cancer [5]. Excitingly, an increasing body of data now indicates that this association might extend to treatment with ionizing radiation. Although most of the supportive data in this area have been derived from cancers that classically overexpress EGFR (notably including head and neck squamous cell carcinoma), there is early evidence of equivalence in breast tumour cells, in which EGFR overexpression can be more modest.

In clinical head and neck cancer, associations have been reported between EGFR overexpression and radioresistance, increased rate of recurrence after radiotherapy, poor local control and reduced patient survival $[7,8]$. Similarly, increased EGFR expression has been directly associated with radioresistance in several model systems, with an inverse correlation reported between magnitude of EGFR expression and radiocurability using a cohort of murine tumours, including mammary cancer, in vivo [9]. In breast cancer in vitro, priming of EGFR signalling with EGF before irradiation acts to increase radioresistance in a time- and dose-dependent manner [10].

Intriguingly, studies in vitro, notably those examining the EGFR-positive MDA-MB-231 breast cancer cell line, have demonstrated that clinical doses of radiation therapy activate EGFR signalling [11-14]. Such activation of EGFR by radiation has been equated with tumour cell proliferative and cytoprotective effects, explaining not only why some EGFR-expressing tumour cells survive inhibition but also the phenomenon of promotion of tumour cell repopu- lation during a course of radiotherapy. It has been suggested that radiation-induced EGFR activation (and hence evasion of inhibition and radioresistance) may be particularly obvious in EGFR-overexpressing cells [9]. Both single and repeated irradiation have been observed to drive EGFR autophosphorylation, with upregulated EGFR expression also reported. Priming of expression and proteolytic cleavage of the key EGFR ligand transforming growth factor- $\alpha$ by irradiation might contribute to this EGFR activation [12]. There is subsequently phosphorylation of the key downstream signalling elements Ras, extracellular regulated (ERK1/2) mitogen-activated protein kinase, p90 ribosomal S6 kinase and AKT [11,12], with a profile of nuclear transcription factors ultimately stimulated [14].

\section{EGFR inhibitory strategies improve radioresponse in tumour types including breast cancer}

An obvious therapeutic consequence of these data is that EGFR blockade might cause radiosensitization. Among the EGFR-inhibitory strategies, furthest advanced in clinical study is the EGFR-selective tyrosine kinase inhibitor ZD1839, which exhibits an acceptable tolerability profile and promising anti-tumour activity in both experimental models and cancer patients [15]. Moreover, supra-additive effects have been observed with this agent in combination with cytotoxics in many tumour models including breast cancer, in which improved response has also been reported when ZD1839 is combined with anti-hormonal procedures [16]. Clinical studies are continuing in both these areas.

However, the article by Huang et al. is among the first to demonstrate successfully the modulation of radioresponse in human tumour cell lines and xenografts by using ZD1839. The study has employed several human squamous carcinoma cell lines established from biopsies of head and neck cancer patients with varying EGFR expression. In all the derived cells in vitro, ZD1839 exerted significant anti-proliferative activity, inducing arrest in the radiosensitive $\mathrm{G} 1$ cell cycle phase (and depletion of the radioresistant $\mathrm{S}$ phase fraction), as well as the enhancement of radiation-induced apoptosis. Clonogenic survival assays revealed that reduced cell survival after radiation was associated with ZD1839. Comparable data demonstrating cooperative anti-proliferative and pro-apoptotic activity of ZD1839 and irradiation have similarly been obtained within experimental non-small cell lung carcinoma, ovarian, colon and breast cancer $[17,18]$.

Huang et al. have subsequently monitored tumour growth in athymic nude mice, revealing that ZD1839 also augments tumour response to radiation in vivo. Combined treatment with radiation and ZD1839 exhibited improved tumour growth inhibition and substantially delayed tumour regrowth in the xenografts examined in comparison with radiation or ZD1839 alone, with an additive (SCC-6 
tumour) or synergistic (SCC-1 tumour) growth inhibitory effect. Substantial effects of radiotherapy plus ZD1839 in vivo, notably long-term tumour regression, have been confirmed in the handful of additional studies reported for a range of cancer cell xenografts, including mammary MDA-MB-468 [17,19]. Huang et al. have shed light on the underlying mechanism of the potency of radiotherapy plus ZD1839 in vivo. In addition to the anti-proliferative and pro-apoptotic effects, a series of elegant experiments revealed that ZD1839 inhibits the early angiogenic process by targeting microvascular endothelial cells, decreasing their cell-cell interaction and disrupting endotube formation, as well as diminishing tumour xenograftinduced neovascularisation of Matrigel plugs. Significant anti-angiogenic effects might result from the ability of ZD1839 to inhibit EGFR-regulated angiogenic growth factor production by tumour cells, such as vascular endothelial growth factor, basic fibroblast growth factor and interleukin-8 [17], and this agent might also directly block EGFR expressed on endothelial cells.

Studies employing alternative EGFR inhibition strategies in irradiated tumour cell xenografts as well as in vitro exhibit equivalent effects to the recent ZD1839 studies from Huang etal. Thus, superior anti-tumour activity versus radiotherapy alone has been reported extensively by this research group when radiotherapy is combined with the anti-EGFR antibody IMC-C225 [20]. Comparable data have also been obtained in various tumour cell lines, including breast cancer, using the EGFR-selective tyrphostin AG1478 [11], EGFR dominant-negative constructs $[21,22]$ and the irreversible pan-erbB inhibitor $\mathrm{Cl}-1033$ [23]. Again, enhanced radiosensitivity seems to result from the induction of apoptosis, the accumulation of cells in radiosensitive cell cycle phases, the downregulation of angiogenic factors and the inhibition of damage repair after irradiation by the redistribution of DNA repair enzyme [20].

\section{Conclusion}

It is clear from the above preclinical studies, exemplified by this new article from Huang et al., that there is increasing rationale for considering anti-EGFR agents such as ZD1839 as a radiosensitizing strategy in cancer management. Indeed, data from a novel clinical investigation by Robert et al. [24] are highly encouraging, in which all 16 locally advanced head and neck cancer patients treated with IMC-C225 plus radiotherapy exhibited an objective response, with no additional toxicity. The results of continuing clinical trials examining ZD1839 (or IMC-C225) in combination with radiotherapy in multiple human malignancies are eagerly awaited.

However, it is important to note that in the study by Huang et al. tumour regrowth was delayed rather than prevented by the use of ZD1839 in combination with radiation, and radiation alone, was nevertheless relatively modest. Thus, although there is obviously considerable promise for this new strategy, our optimism should perhaps be cautious. Moreover, breast cancer cell studies have revealed additional complexities that might potentially influence the outcome of EGFR-targeted inhibitory strategies in combination with radiotherapy if employed in this disease. For example, there is increasing evidence that receptors and signalling pathways other than EGFR might be primed by irradiation $[12,14]$. Multiple erbB tyrosine kinase receptor family members have been observed to be activated indiscriminately by the irradiation of mammary cells, with HER2 being able to influence EGFR activation in response to radiation [13]. Moreover, radiation has been shown to be able to prime several key nuclear transcription factors (such as CCAAT-enhancer-binding protein and Stat1) in breast cancer cells in addition to those that are regulated by EGFR [14]. If we are to employ rationally and gain maximal benefit from inhibitors such as ZD1839 in breast cancer, therefore, it is essential that we more fully elucidate the increasingly complex interrelation between radiation, recruited signal transduction pathways and cellular outcome.

Finally, a key contribution to any success of this combination strategy will be to determine appropriate dosages and sequence of the treatment, and to define accurately which patients to treat. The latter could prove particularly problematic because EGFR overexpression is evident in only about $40 \%$ of breast cancer patients $[4,5,25]$ and elevated expression of the receptor in tumour cells does not always associate with activity of the pathway or a growth inhibitory response to anti-EGFR agents [26]. In turn, experiences in several tumour types with ZD1839 plus chemotherapy demonstrate that anti-tumour responses might not require EGFR overexpression [27]. Indeed, in the study by Huang et al., ZD1839 anti-proliferative responses were most extensive in SCC-13Y tumours that exhibited the lowest EGFR expression, whereas in various tumour cells in vitro, including breast cancer, it is HER2 overexpression, rather than EGFR level, that seems to associate with increased ZD1839 sensitivity [28]. Clearly there remains much to be learned about the action of ZD1839 in clinical breast cancer and its role, if any, in influencing radiosensitivity.

\section{Competing interests}

The authors are holders of research grants funded by AstraZeneca and Merck KGaA.

\section{Acknowledgement}

JMWG is supported by a programme grant from the Tenovus Charity.

\section{References}

1. Withers HR, Taylor JM, Maciejewski B: The hazard of accelerated tumor clonogen repopulation during radiotherapy. Acta Oncol 1988, 27:131-146. 
2. Huang SM, Li J, Armstrong EA, Harari PM: Modulation of radiation response and tumor-induced angiogenesis after epidermal growth factor receptor inhibition by ZD1839 (Iressa). Cancer Res 2002, 62:4300-4306.

3. Wells A: EGF receptor. Int J Biochem Cell Biol 1999, 31:637643.

4. Nicholson RI, Gee JM, Harper ME: EGFR and cancer prognosis. Eur J Cancer 2001, 37 (Suppl 4): S9-S15.

5. Nicholson RI, McClelland RA, Gee JM, Manning DL, Cannon P, Robertson JF, Ellis IO, Blamey RW: Epidermal growth factor receptor expression in breast cancer: association with response to endocrine therapy. Breast Cancer Res Treat 1994, 29:117-125.

6. Dickstein BM, Wosikowski K, Bates SE: Increased resistance to cytotoxic agents in ZR75B human breast cancer cells transfected with epidermal growth factor receptor. Mol Cell Endocrinol 1995, 110:205-211.

7. Miyaguchi M, Olofsson J, Hellquist HB: Expression of epidermal growth factor receptor in glottic carcinoma and its relation to recurrence after radiotherapy. Clin Otolaryngol 1991, 16:466469.

8. Sheridan MT, O'Dwyer T, Seymour CB, Mothersill CE: Potential indicators of radiosensitivity in squamous cell carcinoma of the head and neck. Radiat Oncol Investig 1997, 5:180-186.

9. Akimoto T, Hunter NR, Buchmiller L, Mason K, Ang KK, Milas L: Inverse relationship between epidermal growth factor receptor expression and radiocurability of murine carcinomas. Clin Cancer Res 1999, 5:2884-2890.

10. Wollman R, Yahalom J, Maxy R, Pinto J, Fuks Z: Effect of epidermal growth factor on the growth and radiation sensitivity of human breast cancer cells in vitro. Int J Radiat Oncol Biol Phys 1994, 30:91-98

11. Schmidt-Ullrich RK, Mikkelsen RB, Dent P, Todd DG, Valerie K, Kavanagh BD, Contessa JN, Rorrer WK, Chen PB: Radiationinduced proliferation of the human A431 squamous carcinoma cells is dependent on EGFR tyrosine phosphorylation. Oncogene 1997, 15:1191-1197.

12. Dent P, Reardon DB, Park JS, Bowers G, Logsdon C, Valerie K, Schmidt-Ullrich R: Radiation-induced release of transforming growth factor alpha activates the epidermal growth factor receptor and mitogen-activated protein kinase pathway in carcinoma cells, leading to increased proliferation and protection from radiation-induced cell death. Mol Biol Cell 1999, 10:2493-2506

13. Bowers G, Reardon D, Hewitt T, Dent P, Mikkelsen RB, Valerie K, Lammering G, Amir C, Schmidt-Ullrich RK: The relative role of ErbB1-4 receptor tyrosine kinases in radiation signal transduction responses of human carcinoma cells. Oncogene 2001, 20:1388-1397.

14. Amorino GP, Hamilton VM, Valerie K, Dent P, Lammering G, Schmidt-Ullrich RK: Epidermal growth factor receptor dependence of radiation-induced transcription factor activation in human breast carcinoma cells. Mol Biol Cell 2002, 13:22332244.

15. Ciardiello F, Tortora G: A novel approach in the treatment of cancer: targeting the epidermal growth factor receptor. Clin Cancer Res 2001, 7:2958-2970.

16. Wakeling AE, Nicholson RI, Gee JM: Prospects for combining hormonal and nonhormonal growth factor inhibition. Clin Cancer Res 2001, 7 (Suppl 12): S4350-S4355.

17. Bianco C, Tortora G, Bianco R, Caputo R, Veneziani BM, Caputo R, Damiano V, Troiani T, Fontanini G, Raben D, Pepe S, Bianco AR, Ciardiello F: Enhancement of antitumor activity of ionizing radiation by combined treatment with the selective epidermal growth factor receptor-tyrosine kinase inhibitor ZD1839 (Iressa). Clin Cancer Res 2002, 8:3250-3258.

18. Raben D, Helfrich BA, Chan D, Johnson G, Bunn PA Jr: ZD1839, a selective epidermal growth factor receptor tyrosine kinase inhibitor, alone and in combination with radiation and chemotherapy as a new therapeutic strategy in non-small cell lung cancer. Semin Oncol 2002, 29 (Suppl 4):S37-S46.

19. Williams KJ, Telfer BA, Stratford IJ, Wedge SR: ZD1839 ('Iressa'), a specific oral epidermal growth factor receptortyrosine kinase inhibitor, potentiates radiotherapy in a human colorectal cancer xenograft model. Br J Cancer 2002, 86:1157-1161.

20. Huang SM, Harari PM: Modulation of radiation response after epidermal growth factor receptor blockade in squamous cell carcinomas: inhibition of damage repair, cell cycle kinetics, and tumor angiogenesis. Clin Cancer Res 2000, 6:2166- 2174

21. Contessa JN, Reardon DB, Todd D, Dent P, Mikkelsen RB, Valerie K, Bowers GD, Schmidt-Ullrich RK: The inducible expression of dominant-negative epidermal growth factor receptor-CD533 results in radiosensitization of human mammary carcinoma cells. Clin Cancer Res 1999, 5:405-411.

22. Lammering G, Hewit TH, Hawkins WT, Contessa JN, Reardon DB, Lin PS, Valerie K, Dent P, Mikkelsen RB, Schmidt-Ullrich RK: Epidermal growth factor receptor as a genetic therapy target for carcinoma cell radiosensitization. J Natl Cancer Inst 2001, 93:921-929.

23. Rao GS, Murray S, Ethier SP: Radiosensitization of human breast cancer cells by a novel ErbB family receptor tyrosine kinase inhibitor. Int J Radiat Oncol Biol Phys 2000, 48:1519-1528.

24. Robert F, Ezekiel MP, Spencer SA, Meredith RF, Bonner JA, Khazaeli MB, Saleh MN, Carey D, LoBuglio AF, Wheeler RH, Cooper MR, Waksal HW: Phase I study of anti-epidermal growth factor receptor antibody cetuximab in combination with radiation therapy in patients with advanced head and neck cancer. J Clin Oncol 2001, 19:3234-3243.

25. Klijn JG, Berns PM, Schmitz PI, Foekens JA: The clinical significance of epidermal growth factor receptor (EGF-R) in human breast cancer: a review on $\mathbf{5 2 3 2}$ patients. Endocr Rev 1992, 13:3-17.

26. Bishop PC, Myers T, Robey R, Fry DW, Liu ET, Blagosklonny MV, Bates SE: Differential sensitivity of cancer cells to inhibitors of the epidermal growth factor receptor family. Oncogene 2002, 21:119-127.

27. Sirotnak FM, Zakowski MF, Miller VA, Scher HI, Kris MG: Efficacy of cytotoxic agents against human tumor xenografts is markedly enhanced by coadministration of ZD1839 (Iressa), an inhibitor of EGFR tyrosine kinase. Clin Cancer Res 2000, 6:4885-4892.

28. Moasser MM, Basso A, Averbuch SD, Rosen N: The tyrosine kinase inhibitor ZD1839 ('Iressa') inhibits HER2-driven signaling and suppresses the growth of HER2-overexpressing tumor cells. Cancer Res 2001, 61:7184-7188.

\section{Correspondence}

JMW Gee, Tenovus Centre for Cancer Research, Welsh School of Pharmacy, Cardiff University, Redwood Building, King Edward VII Avenue, Cardiff CF10 3XF, Wales, UK. Tel: +44 292087 5226; fax: +44 292087 5152; e-mail: gee@cardiff.ac.uk 